Keywords: Tritium,

Atmospheric dispersion,

Deposition, Re-emission

Retention: Permanent

\title{
Modeling Tritium Transport, Deposition and Re-emission
}

B. J. Viner

April 2012

Savannah River National Laboratory

Savannah River Nuclear Solutions, LLC Aiken, SC 29808

Prepared for the U.S. Department of Energy under contract number DE-AC09-08SR22470. 
SRNL-STI-2012-00131

Revision 0 
SRNL-STI-2012-00131

Revision 0

\section{DISCLAIMER}

This work was prepared under an agreement with and funded by the U.S. Government. Neither the U.S. Government or its employees, nor any of its contractors, subcontractors or their employees, makes any express or implied:

1. warranty or assumes any legal liability for the accuracy, completeness, or for the use or results of such use of any information, product, or process disclosed; or

2. representation that such use or results of such use would not infringe privately owned rights; or

3. endorsement or recommendation of any specifically identified commercial product, process, or service.

Any views and opinions of authors expressed in this work do not necessarily state or reflect those of the United States Government, or its contractors, or subcontractors.

\section{Printed in the United States of America \\ Prepared for \\ U.S. Department of Energy}




\section{REVIEWS AND APPROVALS}

AUTHORS:

\begin{tabular}{ll}
\hline B. J. Viner, Atmospheric Technologies Group Date
\end{tabular}

TECHNICAL REVIEW:

A. H. Weber, Atmospheric Technologies Group

Date

C. E. Murphy, Environmental Sciences Group

Date

APPROVAL:

C. H. Hunter, Manager, Atmospheric Technologies Group

Date 


\section{EXECUTIVE SUMMARY}

The atmospheric release of tritium oxide (HTO) potentially impacts human health, typically through inhalation or absorption. Due to HTO's similarity to water, vegetation will absorb HTO by solution in the leaf water and then re-emit it, creating a number of secondary sources of HTO. Currently, models used for emergency response at Savannah River Site incorporate the transport and deposition of HTO but do not provide estimates for its potential re-emission from vegetation or soil surface though re-emission could result in prolonged exposure and greater than predicted dose for an individual downwind. A simple model of HTO transport, deposition and re-emission has been developed to examine the potential increase in exposure and dose. The model simulates an initial release of HTO that moves with a mean wind and expands through diffusion as a Gaussian puff. Deposition is modeled using previous estimates of deposition velocity for HTO and re-emission is modeled using a time constant that describes how quickly HTO is transferred between the surface and atmosphere. Additional puffs are created to simulate re-emission of HTO as well as horizontal diffusion across model grid cells. An evaluation of field data indicates that the use of a re-emission module tends to improve model predictions through improved prediction of peak concentration magnitude and location. When considering dose, nearly all of the released material is included in the dose calculation when re-emission is included. Although exposure to HTO through re-emission occurs over a few hours, the incremental increase in dose is relatively small because the atmospheric concentration of re-emitted HTO is much lower than the initial release. 


\section{TABLE OF CONTENTS}

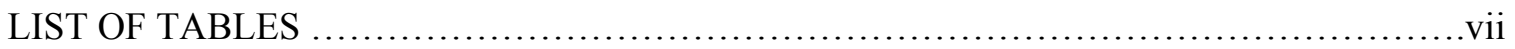

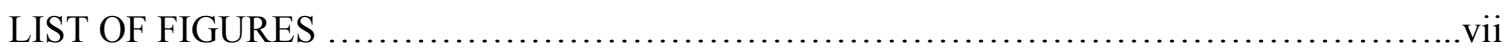

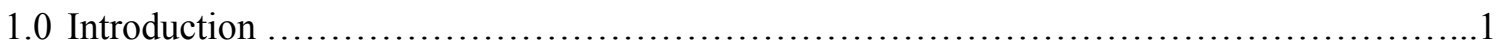

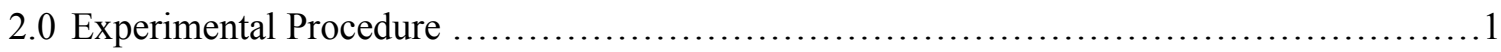

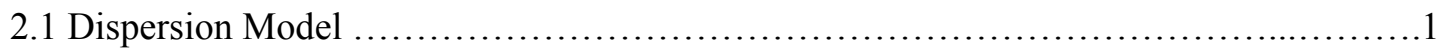

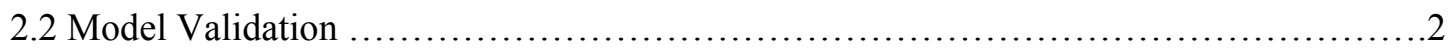

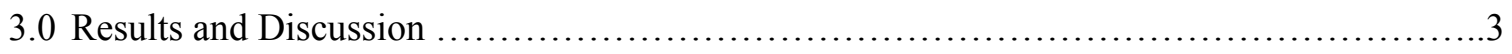

3.1 Effects of Model Parameters.................................................... 3

3.2 Model Validation.........................................................4

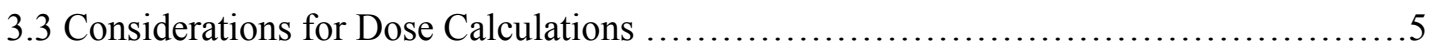

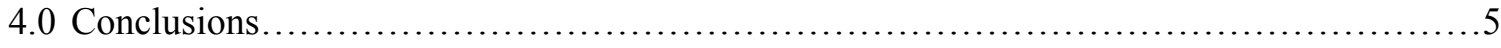

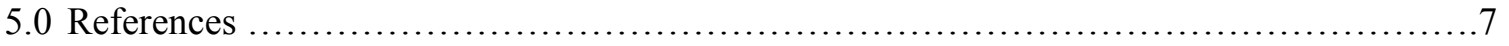


SRNL-STI-2012-00131

Revision 0

\section{LIST OF TABLES}

Table 3-1. Input parameters to the dispersion model for validation simulations .8

Table 3.2. The fraction of a puff release of HTO that passes the site boundary $(\sim 11.5 \mathrm{~km})$ within two hours of first reaching it (expressed as a percent). .8

\section{LIST OF FIGURES}

Figure 3-1. Comparison of plume characteristics 4 hours after release for a wind speed of $2 \mathrm{~ms}^{-1}$ (top) and $5 \mathrm{~ms}^{-1}$ (bottom). Stability class C, a time constant of $2 \mathrm{hr}$ and a release

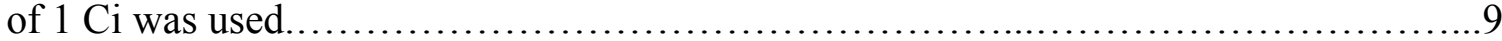

Figure 3-2. Comparison of plume characteristics 4 hours after release for PG Stability class A, an unstable case (top), and class F, a stable case (bottom). A wind speed of 4 $\mathrm{ms}^{-1}$, time constant of $2 \mathrm{hr}$ and a release of $1 \mathrm{Ci}$ was used...........................

Figure 3-3. Comparison of plume characteristics after 15 hours for a residence time constant of 2 hours (top) and 0.4 hours (bottom). A wind speed of $5 \mathrm{~ms}^{-1}$, stability class $\mathrm{C}$ and a release of $100 \mathrm{Ci}$ was used.

Figure 3-4. Comparison of model results (lines) for no re-emission (blue line), and reemission with time constants $\tau=0.4 \mathrm{hr}$ (red line), $\tau=1 \mathrm{hr}$ (green line) and $\tau=2 \mathrm{hr}$ (purple line) with observations (orange dots). Locations 1-5 are for distances at $17.2 \mathrm{~km}$ (a), $18.3 \mathrm{~km}$ (b), $24.6 \mathrm{~km}$ (c), $27.5 \mathrm{~km}$ (d) and $16.3 \mathrm{~km}(\mathrm{e})$. 


\section{LIST OF ABBREVIATIONS}

$\begin{array}{ll}\text { EDT } & \text { Eastern Daylight Time } \\ \text { HTO } & \text { Tritium Oxide } \\ \text { PG } & \text { Pasquill-Gifford (Stability Class) } \\ \text { SRS } & \text { Savannah River Site }\end{array}$




\subsection{Introduction}

Tritium oxide (HTO) in the environment behaves much like water and can be readily absorbed into vegetation as leaf water. After absorption, HTO will also be released back to the atmosphere on time scales ranging from $5 \mathrm{~min}$. to $2 \mathrm{hr}$. (Murphy and Corey 1975). A small amount may become organically bound within the plant (Choi et al. 2002; Ota and Nagai 2011) but this is small enough so as to be negligible (Sweet and Murphy 1984) and it can be assumed that nearly all absorbed HTO will be re-emitted. Brudenell et al. (1997) estimated that this could occur within $48 \mathrm{hr}$.

Most models of radioactive hazards account for deposition (e.g. Atarashi et al. 1998), but modules simulating re-emission of HTO for the purpose of calculating their contribution to the potential radioactive dose have not been adequately developed. Re-emission could be an important factor because it may increase the length of exposure and the dose for an individual located downwind of the release.

Absorption and re-emission of HTO has been examined in various plants. The rate of exchange between the atmosphere and vegetation is proportional to the difference between the atmospheric HTO concentration and the concentration within the plant tissues. The flux of HTO is directed toward the lesser concentration; when the atmospheric concentration is greater than the concentration in the local vegetation, the net movement of tritium is into the vegetation and vice versa. The magnitude of the flux can be modeled using formulations such as Fick's law or deposition velocity

The rate of tritium release has been related to a time constant which describes the resistance of plant stomata to gas flow (Ota and Nagai 2011). The time constant will vary between plants and also depend on the availability of sunlight, among other factors. Using a time constant, the amount of tritium released $(a)$ over a given time period $(t)$ can be described as

$$
a^{\prime}=a d_{c}(1-\exp (-t / \tau))
$$

where $a$ is the concentration of tritium in the atmosphere, $d_{c}$ is the difference between the atmospheric concentration and the concentration in the leaves and $\tau$ is the time constant. Time constants are typically larger at night since most plants close their stomata overnight which increases the resistance to gas exchange with the atmosphere (Atarashi et al. 1998).

This report presents a simple model of HTO transport, deposition to surface vegetation and vegetative re-emission. It is assumed that the surface is sufficiently vegetated that flux between the atmosphere and the soil is negligible. The model is evaluated using measurements from a prior HTO release at Savannah River Site (SRS) which illustrates the impact that re-emission has on plume movement and the magnitude of atmospheric concentration. The results are also examined for how they may impact dose calculations for a downwind individual located at the site boundary. 


\subsection{Procedure}

\subsection{Dispersion Model}

A simple model was created to assess the potential dosimetric impacts of HTO reemission from vegetation. The model uses a three-dimensional Cartesian grid to simulate the transport of HTO as Gaussian puffs in space using a single measurement of wind speed to determine puff movement. The grid can be rotated to match the direction of transport when comparing to real data cases. While puffs only travel in one direction following the mean wind speed, assumed to be the $\mathrm{x}$-direction, they disperse in three dimensions. As the puffs move downwind, their volume increases following

$$
V=\sigma_{x} \sigma_{y} \sigma_{z}
$$

where $\sigma_{x}, \sigma_{y}$ and $\sigma_{z}$ are the standard deviation of the puff size in each direction and are calculated following analytic forms of the Pasquill-Gifford (PG) diffusion curves used in the EPA's ISC3 model (US EPA 2000):

$$
\begin{gathered}
\sigma_{z}=a x^{b} \\
\sigma_{x}=\sigma_{y}=465.116 x\left\{\tan \left[0.017\left(c-d^{*} \log (x)\right)\right]\right\}
\end{gathered}
$$

The ISC 3 model is not designed for puffs, so no $\sigma_{\mathrm{x}}$ exists in the model. It is included here to represent puff diffusion which occurs along the axis of travel and is assumed to be equal to lateral diffusion. The coefficients ' $a$,' ' $b$,' 'c' and 'd' in Eqs. 3 and 4 are specified according to stability conditions and the downwind distance the puff has traveled. The atmospheric stability is categorized according to the PG stability classes and describes the ability of the atmosphere to mix and disperse material. Details for each stability class are discussed in Turner (1970). Theoretically, the volume of a puff will extend to infinity in all directions, but we make the more realistic assumption that the mass of the puff is constrained to a single standard deviation in each direction.

Deposition from the puff to the surface vegetation is assumed to occur equally across the grid cell under the puff's center point. The amount of deposition $(D)$ is determined by the area of the grid cell $(A)$, the average atmospheric concentration of HTO $\left(C_{a t m}\right)$ within a grid cell, the deposition velocity $\left(v_{\text {dep }}\right)$ and the timestep $(\Delta t)$

$$
D=A C_{a t m} v_{d e p} \Delta t
$$

Since Gaussian puffs will grow until they span multiple grid cells, puffs are split when the diameter of the puff $\left(2 \sigma_{x}, 2 \sigma_{y}\right.$ or $\left.2 \sigma_{z}\right)$ exceeds the corresponding grid spacing ( $\Delta x, \Delta y$ or $\left.\Delta z\right)$. The puff is then split into three smaller puffs with $68.28 \%$ (corresponding to one standard deviation of a Gaussian distribution) of the original puff's mass remaining at its current location and two new puffs containing $15.86 \%$ of the original puff's mass created at the center of the neighboring grid cells in the $\mathrm{i}^{\text {th }}$ dimension.

Re-emission from the canopy is determined based on residence time, a characteristic time scale that describes how long HTO remains in vegetation before being returned to the atmosphere. Reemission was modeled similarly to deposition with the exception that the residence time function 
replaces deposition velocity as a measure of how quickly HTO is transferred across the atmosphere/vegetation boundary:

$$
R=V C_{\text {veg }}(1-\exp (-\Delta t / \tau))
$$

where $V$ is the vegetation volume, assumed to be equal to the area of the grid cell and $1 \mathrm{~m}$ deep, $C_{v e g}$ is the HTO concentration in the vegetation and $\tau$ is the residence time constant. When reemission occurs a new puff is created at the center of the grid cell containing the re-emitted material. For dose calculations, it is assumed that all HTO absorbed by vegetation is available for release to the atmosphere, though some of it will be stored as organically-bound by the plant.

The only time new puffs are not created is when the amount of HTO in a new puff does not exceed a minimum value of $10^{-8} \mathrm{Ci}$. This limit was set many orders of magnitude below the value of the initial release so the effect of puffs ignored by the model was negligible. This prevents an accumulation of negligible puffs that tax computing resources.

\subsection{Model Validation}

The model can be validated against an external dataset using records of atmospheric concentrations of HTO at specific points in time and distance from the release source. One such dataset is available from Murphy and Wortham (1991) describing a relatively small tritium release that occurred at SRS on July 31, 1987. Hourly meteorological data and measured concentrations are provided. A release of $4644 \mathrm{Ci}$ of HTO (in addition to a hydrogen form of tritium, HT) occurred between 0918 and 0955 EDT. Meteorological records indicated a $2 \mathrm{~ms}^{-1}$ wind speed at the source and 2-3 $\mathrm{ms}^{-1}$ wind speeds through the surrounding region. Wind direction was approximately from the west, but shifted after 1100 EDT to a south and then southeast wind.

Validation of the model was performed against data collected within the first 6 hours of release. While the shifting winds would affect dispersion toward the end of that period, the reported data suggests the release had diffused toward a uniform concentration over many kilometers at that time, and the wind shifts are not expected to have an immediate impact on local concentrations.

Since the model uses a uniform wind speed, small differences in modeled wind and observed wind could affect the results of the model. This will be illustrated in the model results where the concentration can vary by over an order of magnitude between grid points. Since small errors in wind can create a large difference between the modeled and observed concentration of HTO at a specific point, the linearly-interpolated model results were sampled at a number of points within the grid cell that covers the location of the observation.

\subsection{Results and Discussion}

\subsection{Effects of Model Parameters}

The model was first run for a simple release to ensure that the model's predictions matched expected behaviors in plume modeling. Multiple cases were run varying the wind speed, stability and time constant of the model to check each input for realistic behavior. 
Increasing wind speed resulted in the plume traveling farther in the same amount of time (Figure 3-1). The effect on concentration is not linear because faster downwind transport causes the model to simulate increased diffusion because the stability coefficients in Eqs. 3 and 4 are distance dependent. Changing stability resulted in wider and taller plumes for unstable cases (PG stability class A) and narrower, shorter plumes for very stable class (PG stability class F), consistent with known plume diffusion characteristics (Figure 3-2).

Adjusting the time constant affected the rate of re-emission by the vegetation (Figure 3-3). A long time constant $(\tau=2 \mathrm{hr})$ indicates a slow release from vegetation, while a short time constant $(\tau=0.4 \mathrm{hr}$ ) results in a quicker re-emission of deposited HTO from the vegetation. Using a long time constant lowers the initial peak concentration, but broadens the area it covers as well as creates a longer tail of low concentrations behind the initial release. The shorter time constant creates a higher, shorter peak, and the tail of the plume becomes shorter as re-emitted material depletes more rapidly.

All of these behaviors were consistent with reported characteristics of plume dispersion and reemission from vegetation. The model is next tested against reported data to assess its ability to predict actual events.

\subsection{Model Evaluation}

Model validation was performed against a reported dataset by Murphy and Wortham (1991) which describes a release of HTO from the H-Area at Savannah River Site on July 31, 1987 and reported near-surface atmospheric concentrations of HTO at points in space and time. Model inputs to simulate this case are given in Table 3.1. Atmospheric conditions in the model were assumed not to vary in time.

Measurements at five locations ranging between 17-27 km from the source and 2-6 $\mathrm{hr}$ after the start of the release were used to validate the model. Measurements at a sixth location were also available, but no material was predicted to travel within a kilometer of the measurement at the time it was taken. This is the result of the plume briefly traveling toward the southeast shortly after release (Kurzeja et al. 1988) which is not reflected in the hourly meteorological data provided by Murphy and Wortham (1991).

Comparisons were made for simulations with no-remission and with re-emission following a time constant of 0.4 hours (fastest re-emission), 1.0 hours and 2.0 hours (slowest re-emission). The deposition velocity was set to $0.005 \mathrm{~ms}^{-1}$ which is its estimated daytime deposition velocity (Murphy et al. 2012). Because the model cannot account for small variations in wind speed or direction which could vary the model calculation at a given point by approximately an order of magnitude, model results were sampled at the point of the observation and at a series of points within $1 \mathrm{~km}$ of the observation. Examples of model and observation comparisons are shown in Figure 3-4.

Four of the sampling sets (1-4) are at increasing distances away from the source, tracking the plume as it travels. The fifth sample set represents a re-sampling of a region after the majority of the plume had passed.

The two primary effects of including re-emission are increased atmospheric concentrations except for the leading edge of the plume where no deposited HTO exists to be re-emitted and a slower travel speed for the peak concentration. When re-emission is not included, the predicted plume is 
consistently traveling too quickly, in some cases resulting in a prediction of no HTO in the atmosphere (Sample Sets 3-5); i.e. the HTO has already passed the location. In the other cases, the concentration is predicted to be decreasing as the plume leaves the location while measurements indicate an increasing concentration.

Smaller time constants produced larger peaks in concentration, but concentration decreased more rapidly after the original plume left the region. This is a result of vegetation being predicted to release HTO to the atmosphere more quickly. When the plume had traveled farther downwind and re-emission was a greater factor in determining the atmospheric concentration (Sample sets 3-5), simulating re-emission with a time constant of 0.4 hours tended to perform the best. At locations closer to the source, however, a longer time constant was more accurate. Use of a time constant tended to more accurately predict the trend of the measured concentration for each sample set.

\subsection{Considerations for Dose Calculations}

The features of including re-emission in a dispersion model for HTO - greater downwind peak concentration, a delay in peak concentration and a longer time for exposure - are all important considerations for predicting the dose received by an observer in the path of the plume. Using two bounding deposition velocities to represent slow deposition $\left(0.001 \mathrm{~ms}^{-1}\right)$ and quick deposition $\left(0.005 \mathrm{~ms}^{-1}\right)$ coupled with slow re-emission $(\tau=2 \mathrm{hr})$ or quick re-emission $(\tau=0.4 \mathrm{hr})$, the fraction of a plume predicted to travel $11.5 \mathrm{~km}$ was determined. This distance represents an approximate distance between a potential source and the site boundary of Savannah River Site in the case of an accidental release of HTO (Table 3.2).

In each re-emission case, nearly the entire release was predicted to pass the site boundary, including material originally deposited, within two hours of release. This represents a substantially different scenario for the plume's time of arrival than would be predicted if reemission was ignored.

\subsection{Conclusions}

The work presented here describes a simple model for predicting the transport, deposition and reemission of HTO. A single Gaussian puff, or a series of puffs to represent a plume of HTO is created at a source point and is then transported along a specified wind vector. The growth of the puff was modeled according to published EPA guidelines insofar as they could be attained within the framework of the model. Deposition and re-emission occurred over each grid cell depending on the direction of the gradient of the HTO concentration between the atmosphere and the underlying canopy.

The profile of HTO concentration in the atmosphere was characterized by a maximum at the location of the original puff followed by a tail that decreased with distance from the original plume. The characteristic shape of the plume and decrease in concentration magnitude are expected to remain similar when the original amount of HTO released changes since the formulas specify a percentage of HTO to be deposited or re-emitted over a timestep.

The along-wind profile of magnitude and timing of the peak HTO concentration were affected by the rate of re-emission. Greater re-emission rates, described by lower time constants, resulted in 
increasing magnitude and slower arrival times for the peak concentration. Comparing model results with observations resulted in a better match to the trend of the observation and the magnitude of the observation when re-emission was included. In some cases, not including reemission resulted in predictions of no HTO present when measurements showed otherwise.

The effects of re-emission also impact the prediction of dose received for an individual in the path of a HTO plume. Nearly the entire amount of released HTO was predicted to be included in the 2-hr dose calculation for an individual at the site boundary when re-emission was modeled. This contrasts with conditions when re-emission is not included and suggests that re-emission is an important consideration for material that can be absorbed and released by plant material in a short time frame.

This behavior is consistent with the results of the Puff-Plume Model used by the Atmospheric Technologies Group at Savannah River Site. Puff-Plume does not predict re-emission, but an upper-bound of dose can be determined by turning off the deposition routines. The dose calculation using Puff-Plume without deposition was found to be $180 \%$ of the value when deposition is calculated by the model.

Since this is a simple model, it neglects a number of considerations that would be necessary for more complex applications, such as a three-dimensional varying wind field, the effects of surface characteristics on the wind, and biological considerations that would impact the receptiveness of the underlying canopy to HTO absorption. However, the creation of a re-emission module, which is the focus of this work, may allow for more realistic dispersion of HTO in the future. This model could theoretically be applied to many of the existing modeling frameworks. 
SRNL-STI-2012-00131

Revision 0

\subsection{References}

Atarashi, M., H. Amano, M. Ichimasa and Y. Ichimasa. 1998: Deposition of D2O from air to plant and osil during an experiment of D2O vapor release into a vinyl house. Fusion Engineering and Design, 42: 133-140.

Brudenell, A. J. P., C. D. Collins and G. Shaw. 1997. Dynamics of tritiated water (HTO) uptake and loss by crops after short-term atmospheric release. J. Environmental Radioactivity, 36: $197-218$.

Choi, Y. H., K. M. Lim, W. Y. Lee, S. Diabate and S. Strack. 2002. Tissue free water tritium and organically bound tritium in the rice plant acutely exposed to atmospheric HTO vapor under semi-outdoor conditions. J. Environmental Radioactivity, 58: 67-85.

Chanin, D.I. and Young, M.L. 1998 Code Manual for MACCS2: Volume 1, User's Guide: NUREG/CR-6613/SAND97-0594, Sandia National Laboratories, U.S. Nuclear Regulatory Commission, Washington, DC.

Murphy, C. E. Jr., and J. C. Corey. 1975. Absorption of HTO vapor from the atmosphere by the needles of pine trees. Ecological Society of America, Special Publication 1, Radioecology and Energy resources. Ed. C. Cushing. 108-112.

Murphy, C. E. Jr. and G. R. Wortham. 1991. An atmospheric tritium release database for model comparisons. WSRC-TR-91-671, Rev. 1.

Kurzeja, R. J., C. E. Murphy Jr. and R. W. Taylor. 1988. Dispersion of HT and HTO following an unplanned release of tritium to the atmosphere. Fusion Technology, 14:1111-1113.

Ota, M. and H. Nagai. 2011. Development and validation of a dynamical atmosphere-vegetationsoil HTO transport and OBT formation model. J. Environmental Radioactivity, 102:813823.

Turner, D. B., 1970: Workbook of atmospheric dispersion estimates. PHS Publication No. 999AP-26. U.S. Department of Health, Education and Welfare, National Air Pollution Control Administration, Cinicinatti, $\mathrm{OH}$.

U. S. Environmental Protection Agency, 1995. User's Guide for the Industrial Source Complex (ISC3) Dispersion Models. Volume II - Description of Model Algorithms, EPA-454/B95-003b, Office of Air Quality Planning and Standards, Research Triangle Park, NC. 
SRNL-STI-2012-00131

Revision 0

Table 3-1. Input parameters to the dispersion model for validation simulations

\begin{tabular}{|c|c|}
\hline Variable & Value (units) \\
\hline Wind speed & $2 \mathrm{~ms}^{-1}$ \\
\hline PG Stability Class & $\mathrm{B}$ \\
\hline Quantity of Release & $4644 \mathrm{Ci}$ \\
\hline
\end{tabular}

Table 3-2. The fraction of a puff release of HTO that passes the site boundary $(\sim 11.5 \mathrm{~km})$ within two hours of first reaching it (expressed as a percent).

\begin{tabular}{|c|r|r|r|}
\hline \multirow{2}{*}{$\begin{array}{c}\text { Deposition } \\
\text { Velocity }\left(\mathbf{m s}^{-\mathbf{1}}\right)\end{array}$} & \multirow{2}{*}{$\begin{array}{c}\text { No Re- } \\
\text { emission }\end{array}$} & \multicolumn{2}{|c|}{ w/ Re-emission } \\
\cline { 3 - 4 } & $100.00 \%$ & $100.00 \%$ & $100.00 \%$ \\
\hline 0.000 & $93.33 \%$ & $99.96 \%$ & $100.00 \%$ \\
\hline 0.001 & $70.89 \%$ & $99.70 \%$ & $100.00 \%$ \\
\hline 0.005 & &
\end{tabular}



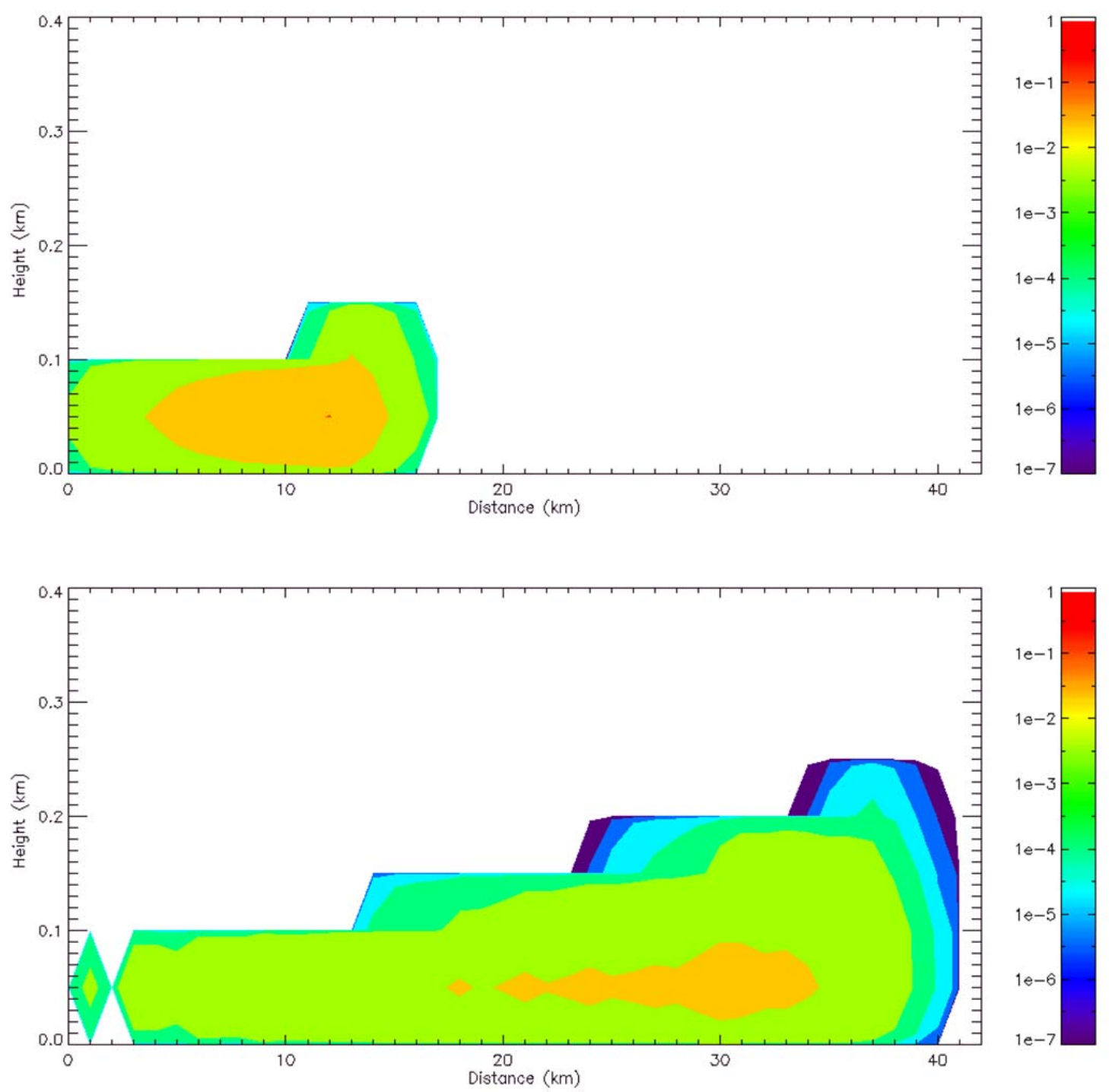

Figure 3-1. Comparison of plume characteristics 4 hours after release for a wind speed of $2 \mathrm{~ms}^{-1}$ (top) and $5 \mathrm{~ms}^{-1}$ (bottom). Stability class C, a time constant of $2 \mathrm{hr}$ and a release of $1 \mathrm{Ci}$ was used. 

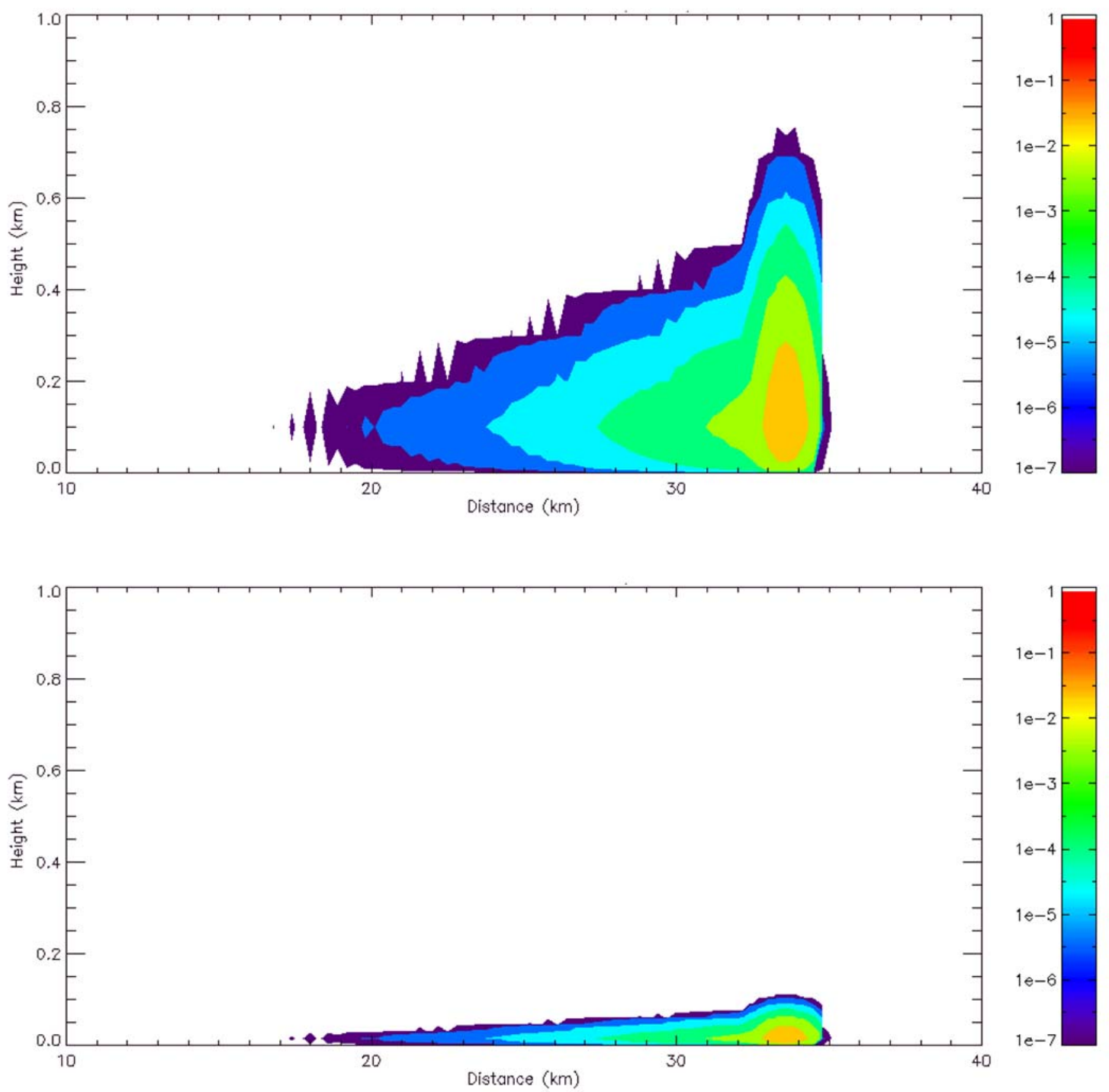

Figure 3-2. Comparison of plume characteristics 4 hours after release for PG Stability class A, an unstable case (top), and class F, a stable case (bottom). A wind speed of $4 \mathrm{~ms}^{-1}$, time constant of $2 \mathrm{hr}$ and a release of $1 \mathrm{Ci}$ was used. 

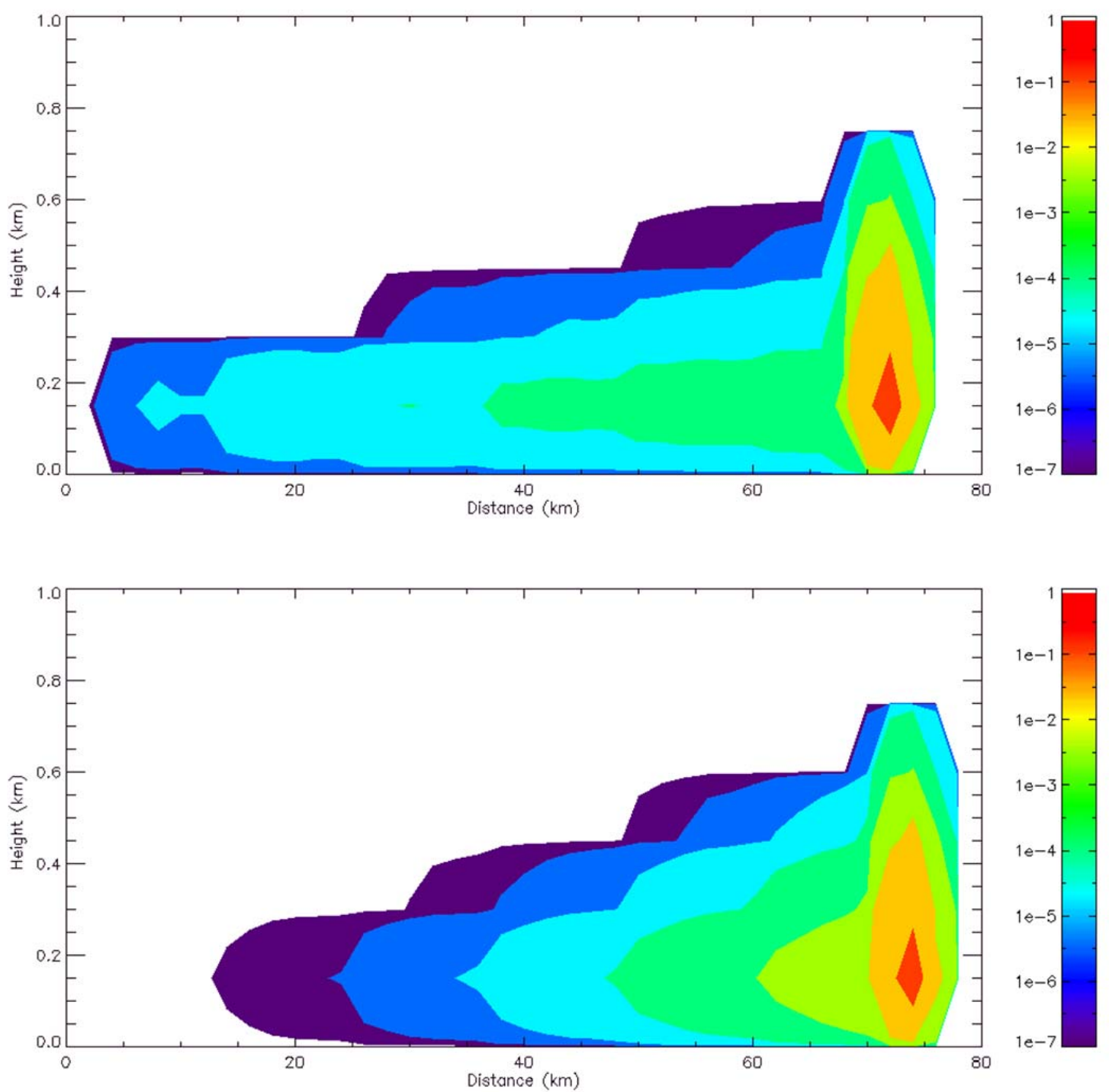

Figure 3-3. Comparison of plume characteristics after 15 hours for a residence time constant of 2 hours (top) and 0.4 hours (bottom). A wind speed of $5 \mathrm{~ms}^{-1}$, stability class $\mathrm{C}$ and a release of $100 \mathrm{Ci}$ was used. 


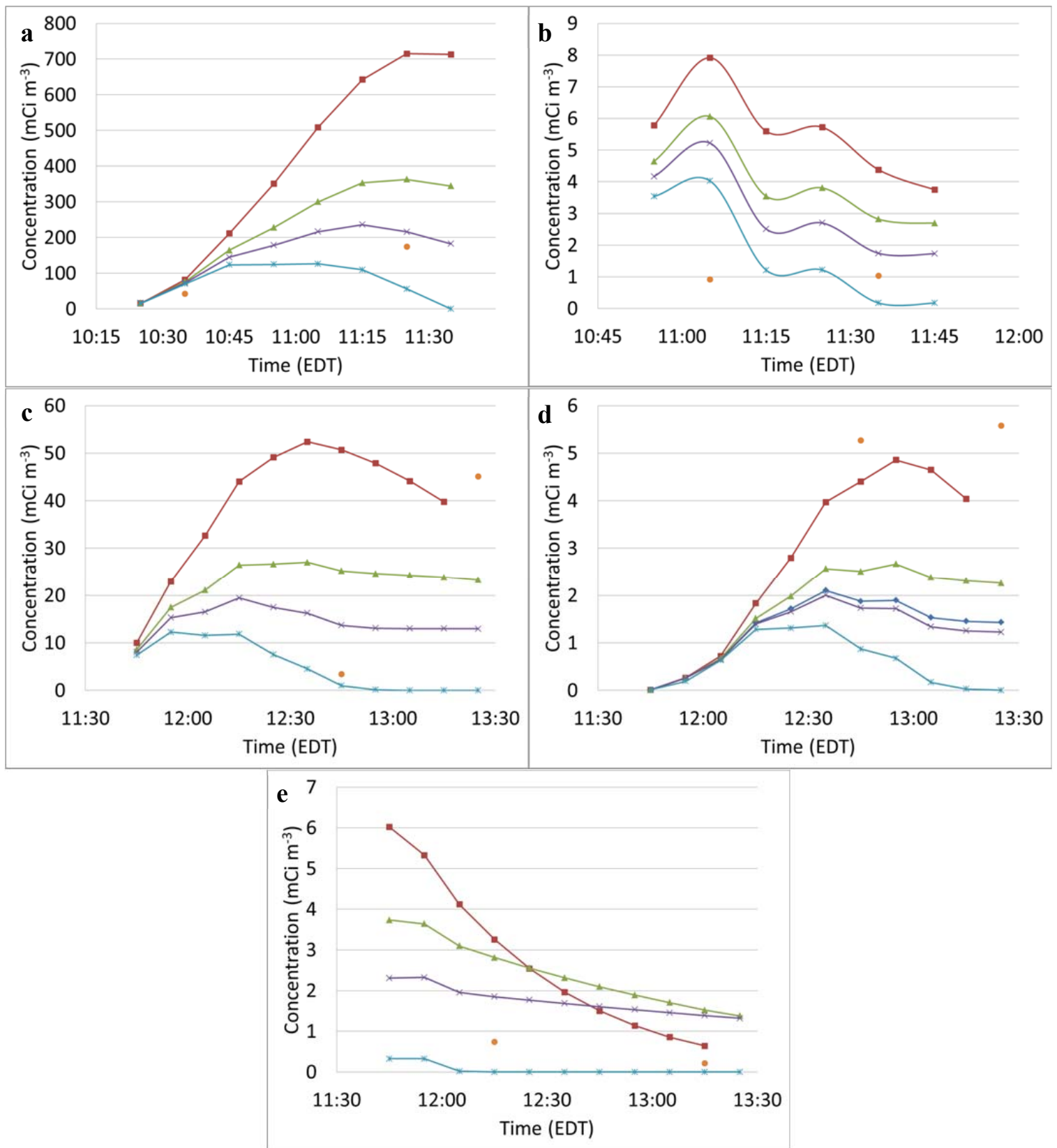

Figure 3-4. Comparison of model results (lines) for no re-emission (blue line), and re-emission with time constants $\tau=0.4 \mathrm{hr}$ (red line), $\tau=1 \mathrm{hr}$ (green line) and $\tau=2$ hr (purple line) with observations (orange dots). Locations 1-5 are for distances at $17.2 \mathrm{~km}(\mathrm{a}), 18.3 \mathrm{~km}$ (b), $24.6 \mathrm{~km}$ (c), $27.5 \mathrm{~km}$ (d) and $16.3 \mathrm{~km}(\mathrm{e})$. 


\section{Distribution:}

J. C. Grove, 730-4B

D. E. Eyler, 773-A

A. E. Burris, 773-A

D. K. Utley, 235-H

D. W. Bickley, 235-H

M. L. Moore, 235-H

L. E. Johnson, 707-C

A. M. Vincent, 707-C

J. C. Guy, 235-11H

B. J. Shaprio, 773-43A

S. K. Elliott, 707-C

E. P. Hope, 707-C

L. M. Chandler, 773-A

A. M. Murray, 773-A

J. J. Mayer, 773-42A

R. L. Buckley, 773-A

K. Chen, 773-A

S. R. Chiswell, 773-A

R. J. Kurzeja, 773-A

M. J. Parker, 773-A

B. J. Viner, 773-A

D. W. Werth, 773-A

G. T. Jannik, 773-42A 